\title{
Community Pharmacist and Clinical Pharmacist Interventions using MMAS-8, FACIT, SF-12 among Pulmonary TB Patients Receiving Anti-TB Drugs from Urban Community Pharmacies, South India
}

\author{
Uday Kumar Rangaswamy, Madiwalayya Shivakantayya Ganachari* \\ Department of Pharmacy Practice, KLE College of Pharmacy, KLE Academy of Higher Education and Research, Belagavi, Karnataka, \\ INDIA.
}

\begin{abstract}
Aim and Objectives: To determine the professional interaction between community pharmacist and clinical pharmacist during the treatment of pulmonary tuberculosis (TB) patients at urban community pharmacy. Methods: A randomized controlled study was conducted in the urban area of Belagavi city, India. Community pharmacist and clinical pharmacist intervention using Developed KAP (Knowledge, Attitude and practice) questionnaires, Morisky Medication Adherence Scale (MMAS-8), FACIT- Satisfaction with Pharmacist Scale, Health-related QoL (SF-12). Results: A total of 350 community pharmacies were surveyed for this study. Total of $87(37.7 \%)$ community pharmacies had a working dispensable stock of anti-TB medicines first-line. Majority of patients $29(58 \%)$ from the urban area. Adherence behavior was changed from $2 \%$ to $92 \%$ (at follow-up visit 3 ). Patient Statistical significance $\left({ }^{*} p<0.05\right)$ towards clinical and community pharmacists by patients. All health-related components of QoL SF-12 were significantly improved at six months, except for the energy and fatigue (VT) portion. Conclusion: We noticed that the community pharmacists who took part in our research demonstrated a clear tendency to cooperate with clinical pharmacist, but that disposition has not yet been reciprocal. Community pharmacists must also become acquainted with professional interactions in the health system of (TB) during their educational classes, during their continuing education in pharmacy and after graduation and try to eliminate the existing imperfections.
\end{abstract}

Key words: Community Pharmacists, Clinical Pharmacists, Pulmonary Tuberculosis, Quality of life, Medication Adherence, Knowledge, Attitude and Practice (KAP).

\section{INTRODUCTION}

Pharmacy is a major discipline in health which contributes to a country's growth. ${ }^{1}$ Pharmacists play a crucial role in the production, promotion and control of pharmaceutical goods, the delivery of pharmaceutical treatment facilities and the diffusion of their expertise by education and study. ${ }^{2,3}$ In fact, pharmacists are essential representatives of a multidisciplinary healthcare system that advocates about patients and plays a significant role in ensuring all pharmaceutical drugs are utilized sensibly. ${ }^{4,5}$ Expanded functions of clinical pharmacists support cost-effective treatment. ${ }^{6}$ These functions are widely known and considered essential parts of the healthcare systems in many countries, ${ }^{6-8}$ including in developed countries. ${ }^{9}$ Local pharmacists are ideally equipped to support patients knock down obstacles to adherence. Many findings suggest that patient monitoring by group pharmacists can boost compliance, commitment, self-care and, in certain situations, the restoration of a net economy. ${ }^{10}$
Submission Date: 16-04-2020; Revision Date: 22-06-2020; Accepted Date: 09-09-2020

DOI: 10.5530/ijper.54.4.216 Correspondence: Dr. Madiwalyya Shivakantayya Ganachari Professor and Head, Department of Pharmacy Practice, KLE College of Pharmacy, KLE Academy of Higher Education and Research, Belagavi-590010, Karnataka, INDIA.

Phone: +91-9448634457

E-mail: msganachari@gmail. com

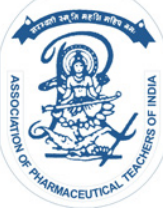

www.ijper.org 
To end the TB epidemic by 2035, the End TB Policy of the World Health Organization (WHO) emphasizes leveraging the aggregate advantages of health policies and programs by involving a far broader spectrum of partners through government, societies and thus, the private sector. In 2013, the WHO estimated that 3 million people struggle to induce a quality-assured TB diagnosis per year and often receive care for TB treatment from several private providers. Private prescription pharmacy stores are a crucial ally in ensuring accessible and high-quality care services are listed to patients in their community. The WHO's first publicprivate mix (PPM) solution to TB describes the variety of treatments available especially for no doctors, such as specialty pharmaceuticals, pharmacists and conventional heaers. ${ }^{11}$ Inter professional relationships are essential in obtaining clinical pharmacists' help in performing this kind of work... In view of this, present study was to evaluate clinical pharmacy services between community pharmacists and clinical pharmacists among pulmonary TB patients, through training and standardized questionnaires.

\section{MATERIALS AND METHODS}

\section{Study design and study settings}

A randomized controlled study was conducted in the urban area of Belagavi City, India.

\section{Study instruments and Questionnaires design Knowledge, Attitude and practice}

The questionnaire was designed to test knowledge, attitude and practice. The survey consisted of three sections. The first part consisted of group demographic details (gender, age, education, experience, etc.) of the respondents. The second part ('True' or 'false') gave rise to awareness (TB transmission, TB symptoms, TB infection). The third element ('Yes or No') decided community pharmacists 'attitude and practice (patient therapy, Public-Private Combination, TB care, Application use).

\section{Morisky Medication Adherence Scale (MMAS-8)}

The 8-item Morisky Medication Adherence Scale (MMAS-8) is one of the best self-reporting measures for assessing medication enforcement. The MMAS-8's reliability and validity will or have already been evaluated in many languages through diverse cultures, environments and diseases. ${ }^{12}$

\section{FACIT- Satisfaction with pharmacist}

The seven elements on the Pharmacist Satisfaction (SWiP) scale were graded on a Likert scale of five points $(0=$ not at all to $4=$ very much $) .{ }^{13}$

\section{Health-related QoL (SF-12)}

The SF-12 is a multipurpose short form survey of 12 questions. The questions were grouped, graded and weighted to establish two measures that offer insight into mental and physical activity and general quality of life relevant to health. ${ }^{14}$

\section{Program context}

The intervention was a nested in Belagavi, India urban city in a partnership between KLE Pharmacy College and district TB control center, Deputy drug controller regional office.

\section{Detailed study procedure}

Surveyed 350 community pharmacies. After the survey, 60 Community pharmacies from various area have been hired for the research based on their consent to participate in the study. This KAP questionnaire consists of 39 questions, of which 25 are related to knowledge, 19 questions are attitude and practice aspects. Each reported all clinical pharmacy procedures conducted with the community pharmacists. Using the same questionnaires follow up test recorded $\left(3^{\text {rd }}\right.$ and $6^{\text {th }}$ month) of the study.

Randomized only 30 community pharmacists who are interested to become DOTS (Directly observed treatment, short-course) provider (treatment supporter). In the control group (15 community pharmacies) the only checklist is provided for the number of dispensing anti-TB drugs to patients which is non-clinical pharmacy services (Without clinical pharmacist). In Study Intervention group (15 community pharmacies) recruiting pulmonary TB patients and to check the compliance (with clinical pharmacy) using Morisky Medication Adherence Scale (MMAS-8), FACIT- Satisfaction with pharmacist, SF-12 scale (Figure 1). In control groups, community pharmacy people will not have any interaction between clinical pharmacists and they were provided with only check list with the details of to how many patients they have dispensed the drugs.

\section{Intervention components}

Training: In the beginning, there was an immersive educational session (pre-test) and two follow-up posts 


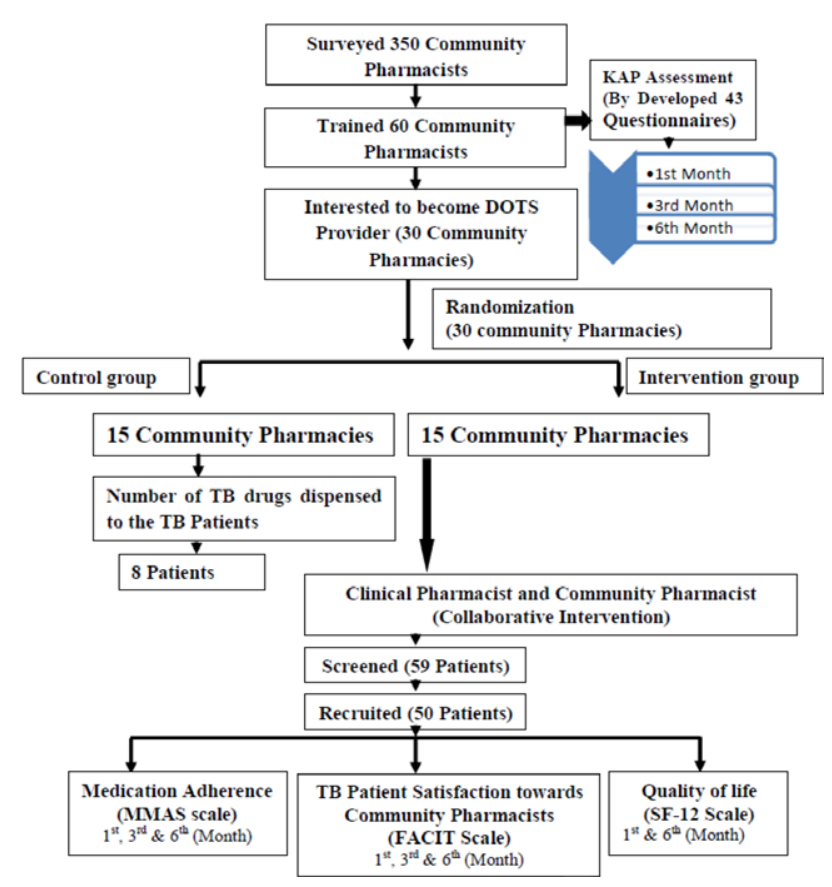

Figure 1: Detailed Study procedure.

$\left(3^{\text {rd }}\right.$ and $6^{\text {th }}$ months). The topics include symptomology of TB, diagnostic testing, TB screening, antibiotic stewardship and recording, referral practices for research.

Assessment of knowledge attitude and practice: The questionnaire was created to test awareness, attitude and action. The survey consisted of three sections. The first part consisted of group demographic details (gender, age, education, experience, etc.) of the respondents. The second part ('True' or 'false') gave rise to awareness (TB transmission, TB symptoms, TB infection). The third element ('Yes or No') decided neighborhood pharmacists 'attitude and practice (patient therapy, Public-Private combination, TB care, Application use).

Supervision and monitoring: Clinical pharmacists have been visited for post follow up ( $3^{\text {rd }}$ and $6^{\text {th }}$ months) to address the implementation of community pharmacists 'Awareness attitude and practice to provide the best TB services.

\section{Ethical approval}

The thesis was accepted by the KLE Academy of Higher Education and Research Ethics Committee by letter-number KAHER / Ethics/2019-19/D-129. The informed consent was obtained from all participants.

\section{Statistical analysis}

The data obtained through the questionnaire was entered and statistical analysis was performed using
IBM SPSS Statistics. Cochran's Q test was used for two follow-up phases, Karl Pearson's coefficient of correlation was used to measure correlation, to evaluate the degree of information and Wilcoxon matched-pairs test attitude and experience was used. $P<0.05$ was considered to be statistically significant.

\section{RESULTS}

\section{Survey of community pharmacies}

Survey on community pharmacy is shown in Figure 2: A total of 312 were community pharmacies were surveyed for this study. The pharmacy practitioners were educated in pharmacy practice with 95.8\% of them holding a diploma degree, $3.84 \%$ with a Bachelor's degree and $0.32 \%$ with a Master's degree.

\section{Dispensing Anti-TB drugs}

Dispensing of methods of anti-TB drugs shown in Figure 3: A total of $87(37.7 \%)$ community pharmacies had a working dispensable stock of first-line anti-TB drugs and 225 pharmacy counters were not having the same in control group 15 community pharmacists dispensed drugs to eight patients.

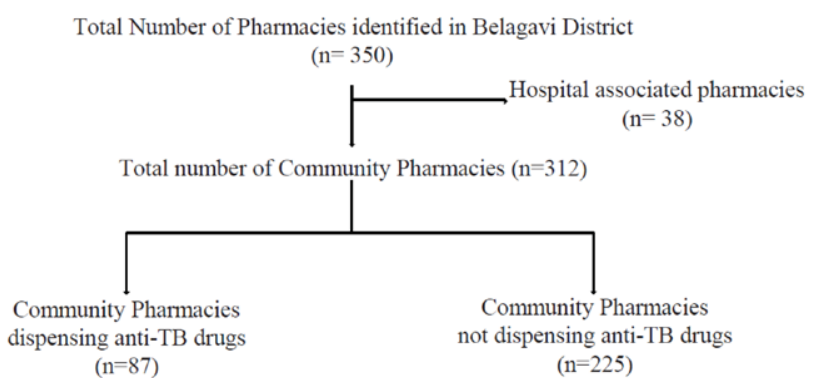

Figure 2: Survey of Community pharmacies in Urban city.

Figure: Storing of Anti-tb wise distribution

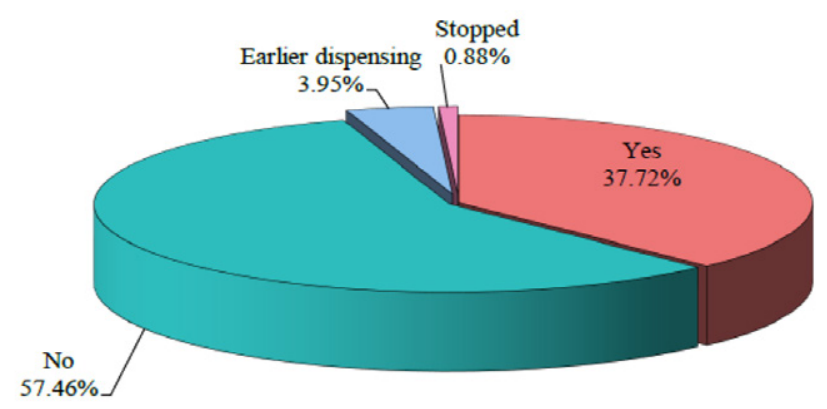

Figure 3: Dispensing of Anti-TB Drugs in Community Pharmacies. 


\section{Table 1: Demographic profile of pharmacists.}

\begin{tabular}{|c|c|c|}
\hline $\begin{array}{l}\text { Demographic } \\
\text { profile }\end{array}$ & $\begin{array}{l}\text { No. of Community } \\
\text { pharmacists }\end{array}$ & $\begin{array}{c}\% \text { of Community } \\
\text { pharmacists }\end{array}$ \\
\hline \multicolumn{3}{|l|}{ Gender } \\
\hline Male & 58 & 96.67 \\
\hline Female & 2 & 3.33 \\
\hline \multicolumn{3}{|l|}{ Education } \\
\hline B. Pharm. & 3 & 5.00 \\
\hline D. Pharm. & 57 & 95.00 \\
\hline \multicolumn{3}{|l|}{ Age groups } \\
\hline$<=29$ yrs & 13 & 21.67 \\
\hline $30-39$ yrs & 17 & 28.33 \\
\hline $40-49$ yrs & 19 & 31.67 \\
\hline$>=50 \mathrm{yrs}$ & 11 & 18.33 \\
\hline \multicolumn{3}{|l|}{ Experience } \\
\hline $1-10$ yrs & 21 & 35.00 \\
\hline $11-20$ yrs & 24 & 40.00 \\
\hline$>=21 \mathrm{yrs}$ & 15 & 25.00 \\
\hline Total & 60 & 100.00 \\
\hline
\end{tabular}

Training of community pharmacies and assessment of knowledge, attitude and practice of community pharmacists

1. Before training (on the time of training)

2. $1^{\text {st }}$ Follow-up ( $3^{\text {rd }}$ month)

3. $2^{\text {nd }}$ Follow-up (6 $6^{\text {th }}$ month)

Table 1 illustrates the demographic characteristics of the 60 community pharmacists who participated in the current study. The majority of community pharmacists were males $(96.67 \%)$. The highest number of pharmacists was holding a Diploma in Pharmacy (95\%). There were more in the age group $40-49$ years $(31.67 \%)$. Pharmacists had 11-20 years of experience (40\%) compared with pharmacists that had 1-10 years of experience (35\%).

Comparison of baseline, 3 and 6 months time points with knowledge attitude and practice by independent $t$-test (Table 2 and Table 3).

\section{Patient characteristics}

Out of 50 pulmonary TB patients studied, $35(70 \%)$ were male and $15(30 \%)$ were female. Some patients are of $(n=23)(46 \%)$ were in the age group of 18-30 years. The majority of patients $29(58 \%)$ from the urban area. Fifteen patients $(30 \%)$ were in weight groups $51-60 \mathrm{Kg}$. $35(70 \%)$ were married, $14(28 \%)$ were Degree graduate (University level), 31 (62\%) patients were employed (Table 4). $32(64 \%)$ of patients were no social habits (Table 5).

Table 2: Comparison of baseline, 3 months and 6 months time points with knowledge scores towards
Tuberculosis by dependent $t$-test.
\begin{tabular}{|c|c|c|c|c|c|c|c|}
\hline Time points & Mean & Std.Dv. & Mean Diff. & SD Diff. & $\%$ of change & Paired $t$ & $p$-value \\
\hline Baseline & 17.75 & 3.49 & & & & & -16.3703 \\
\hline 3 months & 23.92 & 1.28 & -6.17 & 2.92 & -34.74 & $<0.001$ \\
\hline Baseline & 17.75 & 3.49 & & & & & \\
\hline 6 months & 24.90 & 0.30 & -7.15 & 3.47 & -40.28 & -15.9693 & $<0.001$ \\
\hline 3 months & 23.92 & 1.28 & & & & & \\
\hline 6 months & 24.90 & 0.30 & -0.98 & 1.28 & -4.11 & -5.9409 & $<0.001$ \\
\hline
\end{tabular}

Table 3: Comparison of baseline, 3 months and 6 moths time points with attitude and practice scores towards
Tuberculosis by dependent t test.
\begin{tabular}{|c|c|c|c|c|c|c|c|}
\hline Time points & Mean & Std.Dv. & Mean Diff. & SD Diff. & $\%$ of change & Paired $t$ & $p$-value \\
\hline Baseline & 8.72 & 3.57 & & & & & \\
\hline 3 months & 13.83 & 0.49 & -5.12 & 3.48 & -58.70 & -11.3757 & $<0.001$ \\
\hline Baseline & 8.72 & 3.57 & & & & & \\
\hline 6 months & 13.93 & 0.25 & -5.22 & 3.56 & -59.85 & -11.3624 & $<0.001$ \\
\hline 3 months & 13.83 & 0.49 & & & & & \\
\hline 6 months & 13.93 & 0.25 & -0.10 & 0.35 & -0.72 & -2.1872 & $0.0327^{*}$ \\
\hline
\end{tabular}

${ }^{*} p<0.05$ 


\section{Table 4: Socio demographic profile of patients.}

\begin{tabular}{|c|c|c|}
\hline $\begin{array}{c}\text { Socio demographic } \\
\text { profile }\end{array}$ & No. of patients & $\%$ of patients \\
\hline \multicolumn{3}{|l|}{ Sex } \\
\hline Male & 35 & 70.00 \\
\hline Female & 15 & 30.00 \\
\hline \multicolumn{3}{|l|}{ Age groups } \\
\hline$<=30$ yrs & 23 & 46.00 \\
\hline $31-40$ yrs & 8 & 16.00 \\
\hline $41-50$ yrs & 5 & 10.00 \\
\hline$>=51 \mathrm{yrs}$ & 14 & 28.00 \\
\hline Mean age & 37.86 & \\
\hline SD age & 16.94 & \\
\hline \multicolumn{3}{|l|}{ Location } \\
\hline Rural & 29 & 58.00 \\
\hline Urban & 21 & 42.00 \\
\hline \multicolumn{3}{|l|}{ Wight groups } \\
\hline$<=40 \mathrm{~kg}$ & 11 & 22.00 \\
\hline $41-50 \mathrm{~kg}$ & 13 & 26.00 \\
\hline $51-60 \mathrm{~kg}$ & 15 & 30.00 \\
\hline $61-70 \mathrm{~kg}$ & 9 & 18.00 \\
\hline$>=71 \mathrm{~kg}$ & 2 & 4.00 \\
\hline Mean Wight & 50.20 & \\
\hline SD Wight & 14.20 & \\
\hline \multicolumn{3}{|l|}{ Marital Status } \\
\hline Married & 35 & 70.00 \\
\hline Unmarried & 15 & 30.00 \\
\hline \multicolumn{3}{|l|}{ Education } \\
\hline Intermediate school & 13 & 26.00 \\
\hline No Schooling & 5 & 10.00 \\
\hline Primary level & 9 & 18.00 \\
\hline Secondary level & 9 & 18.00 \\
\hline University & 14 & 28.00 \\
\hline \multicolumn{3}{|l|}{ Occupation } \\
\hline Employed & 31 & 62.00 \\
\hline Un employed & 19 & 38.00 \\
\hline
\end{tabular}

\section{Morisky Medication Adherence Scale (MMAS-8)}

As shown in Table 6 and Table 7 clinical and community pharmacists reported adherence from 4 weeks (First visit), 3 months (follow-up visit 1), 6 months (follow-up visit 2) of standard TB treatment. The mean MMAS-8 value was in the context of medium conformity over all time points for all participants. Table 6 and Table 7 Shows statistical significance $(\mathrm{P}=0.0001)$ in follow up visit 2 and visit 3 . Based on the medication adherence grading of MMAS-8, Most of pulmonary TB patients reported high adherence at all follow-up visits during treatment. This low level and a medium level of

\section{Table 5: Habits wise distribution of patients.}

\begin{tabular}{|c|c|c|}
\hline Habits & No. of patients & \% of patients \\
\hline Alcohol & 7 & 14.00 \\
\hline Alcohol, Smoking & 3 & 6.00 \\
\hline Alcohol, Smoking, Tobacco & 1 & 2.00 \\
\hline Alcohol, Tobacco & 2 & 4.00 \\
\hline Smoking, Tobacco & 2 & 4.00 \\
\hline Tobacco & 3 & 6.00 \\
\hline No habit & 32 & 64.00 \\
\hline Total & 50 & 100.00 \\
\hline
\end{tabular}

adherence remained unchanged in Visit $14^{\text {th }}$ week). $58 \%$ medium adherence and 4\% high adherence of patients their adherence behavior were changed from low adherence after 3 months (at follow-up visit 2). However, adherence behavior was changed from 2 to $92 \%$.

\section{FACIT- Satisfaction with Pharmacist}

As shown in Table 8 statistical significance (-16.0521, paired $t$ test) towards clinical and community pharmacists by patients.

\section{SF-12 scale}

According to Table 9 there was a substantial increase in all health-related components of QoL SF-12 at six months, with the exception of the strength and exhaustion (VT) portion (Table 3). There was also substantial change in physical and emotional well-being ratings.

\section{DISCUSSION}

Several pharmacist-physician joint experiments were carried out from a physician's point of view, but there are only a few studies on this collaboration from the viewpoint of community pharmacists and clinical pharmacists. According to our literature survey, this is the first study to examine the attitudes of community pharmacists in collaboration with the clinical pharmacist in India. This domain measures the extent of interdependence between community pharmacists and clinical pharmacist. Hess et al. conducted a retrospective observational study analyzing prescription records of university students in Southern California with latent TB infections receiving treatment from university pharmacists administered community pharmacy to assess their isoniazid completion rate of 9 and 6 months. ${ }^{15}$ The completion rate for 9 months isoniazid is $59 \%$ and the completion rate for 6 months is $67 \%$. At the 
Table 6: MMAS-8, Comparison of $1^{\text {st }}$ month (First visit), 3 month (follow-up visit 1) and 6 month (follow-up visit

2) time points with medical adherence scores by dependent $t$ test.

\begin{tabular}{|c|c|c|c|c|c|c|c|}
\hline Time points & Mean & Std.Dv. & Mean Diff. & SD Diff. & \% of effect & Paired $\boldsymbol{t}$ & $\boldsymbol{P}$-value \\
\hline $1^{\text {st }}$ month & 4.49 & 1.69 & & & & & \\
\hline 3 months & 6.51 & 0.76 & -2.02 & 1.92 & -44.99 & -7.4220 & $0.0001^{*}$ \\
\hline $1^{\text {st }}$ month & 4.49 & 1.69 & & & & & \\
\hline 6 months & 7.92 & 0.27 & -3.43 & 1.71 & -76.39 & -14.1848 & $0.0001^{*}$ \\
\hline 3 months & 6.51 & 0.76 & & & & & \\
\hline 6 months & 7.92 & 0.27 & -1.41 & 0.78 & -21.66 & -12.7485 & $0.0001^{*}$ \\
\hline
\end{tabular}

$* p<0.05$

\begin{tabular}{|c|c|c|c|c|c|c|}
\hline Adherence & $1^{\text {st }}$ month & $\%$ & 3 months & $\%$ & 6 months & $\%$ \\
\hline Low level & 50 & 100.00 & 19 & 38.00 & 0 & 0.00 \\
\hline Medium level & 0 & 0.00 & 29 & 58.00 & 4 & 8.00 \\
\hline High level & 0 & 0.00 & 2 & 4.00 & 46 & 92.00 \\
\hline Total & 50 & 100.00 & 50 & 100.00 & 50 & 100.00 \\
\hline $1^{\text {st }}$ month vs 3 months & \multicolumn{6}{|c|}{ Wilcoxon matched pairs, $Z=4.8599, p=0.0001^{*}$} \\
\hline $1^{\text {st }}$ month vs 3 months & \multicolumn{6}{|c|}{ Wilcoxon matched pairs, $Z=6.1540, p=0.0001^{*}$} \\
\hline 3 months vs 3 months & \multicolumn{6}{|c|}{ Wilcoxon matched pairs, $Z=5.9052, p=0.0001^{*}$} \\
\hline
\end{tabular}

$* p<0.05$

Table 8: FACIT scale- Satisfaction with Pharmacist, Comparison of $1^{\text {st }}$ month, 3 months and 6 months time
points with FACIT scores by dependent $t$ test.
\begin{tabular}{|c|c|c|c|c|c|c|c|}
\hline Time points & Mean & Std.Dv. & Mean Diff. & SD Diff. & \%of effect & Paired $t$ & $P$-value \\
\hline $1^{\text {st }}$ month & 25.24 & 0.74 & & & & & \\
\hline 3 months & 27.44 & 0.91 & -2.20 & 1.23 & -8.72 & -12.6587 & $0.0001^{*}$ \\
\hline $1^{\text {st }}$ month & 25.24 & 0.74 & & & & & \\
\hline 6 months & 27.72 & 0.64 & -2.48 & 1.09 & -9.83 & -16.0521 & $0.0001^{*}$ \\
\hline 3 months & 27.44 & 0.91 & & & & & \\
\hline 6 months & 27.72 & 0.64 & -0.28 & 0.64 & -1.02 & -3.0929 & $0.0001^{*}$ \\
\hline
\end{tabular}

${ }^{*} p<0.05$

pharmacy, the large number of foreign-born patients may have affected the findings of the study as language and culture could be obstacles to communication. The risk of counting drug inaccuracy can also pose a limitation of this study because patients can discard tablets or misrepresented the number of tablets taken to complete TB care. $^{15}$

Upon the launch of a clinical pharmacy program, this research investigated the working relationships of community pharmacists and commercial pharmacists in an urban community pharmacies. The study found that community-based clinical pharmacy programs are multifaceted and require taking into account the professional understanding of the function and skills of the pharmacist. Clark et al. A retrospective, randomized case- a study was performed among first- TB- in Turkey to assess the effect of the pharmacist- TB therapy education on patient progress in attending scheduled follow- visits and adherence to drug therapy. ${ }^{16}$

Infected patients admitted to the hospital for the first time were either randomized to obtain TB education from a community pharmacist and clinical pharmacist. Patient attendance at planned follow- clinic visits and urinalysis for isoniazid exposure had better results in the educational community supported by pharmacists. A strength of this research is that patients have been 


\begin{tabular}{|c|c|c|c|c|c|c|c|c|}
\hline Variables & $\begin{array}{c}\text { Time } \\
\text { points }\end{array}$ & Mean & Std.Dv. & Mean Diff. & SD Diff. & $\%$ of effect & Z-value & $P$-value \\
\hline \multirow[t]{2}{*}{ Total SF-12 } & $1^{\text {st }}$ month & 38.84 & 2.01 & & & & & \\
\hline & 6 months & 25.22 & 2.66 & 13.62 & 2.66 & 35.07 & 36.2544 & $0.0001^{*}$ \\
\hline \multirow[t]{2}{*}{ General Health } & $1^{\text {st }}$ month & 2.46 & 0.50 & & & & & \\
\hline & 6 months & 2.90 & 0.30 & -0.44 & 0.61 & -17.89 & -5.0883 & $0.0001^{*}$ \\
\hline \multirow[t]{2}{*}{ Physical functioning } & $1^{\text {st }}$ month & 4.46 & 0.50 & & & & & \\
\hline & 6 months & 3.50 & 0.76 & 0.96 & 0.86 & 21.52 & 7.9284 & $0.0001^{*}$ \\
\hline \multirow[t]{2}{*}{ Role Physical } & $1^{\text {st }}$ month & 7.46 & 0.50 & & & & & \\
\hline & 6 months & 4.24 & 1.32 & 3.22 & 1.40 & 43.16 & 16.2179 & $0.0001^{*}$ \\
\hline \multirow[t]{2}{*}{ Role Emotional } & $1^{\text {st }}$ month & 8.46 & 0.50 & & & & & \\
\hline & 6 months & 2.60 & 0.67 & 5.86 & 0.45 & 69.27 & 91.6319 & $0.0001^{*}$ \\
\hline \multirow[t]{2}{*}{ Social Functioning } & $1^{\text {st }}$ month & 4.00 & 0.00 & & & & & \\
\hline & 6 months & 1.52 & 0.50 & 2.48 & 0.50 & 62.00 & 34.7478 & $0.0001^{*}$ \\
\hline \multirow[t]{2}{*}{ Body Pain } & $1^{\text {st }}$ month & 4.54 & 0.50 & & & & & \\
\hline & 6 months & 1.10 & 0.30 & 3.44 & 0.61 & 75.77 & 39.7813 & $0.0001^{*}$ \\
\hline \multirow[t]{2}{*}{ Mental Health } & $1^{\text {st }}$ month & 7.46 & 0.50 & & & & & \\
\hline & 6 months & 9.36 & 0.69 & -1.90 & 0.51 & -25.47 & -26.6000 & $0.0001^{*}$ \\
\hline
\end{tabular}

${ }^{*} p<0.05$

randomized to receive or not receive pharmacist education and, in addition to testing adherence qualitatively, patients have agreed to urine analyzes that quantitatively assess adherence and provide more proof for or against the effect of pharmacist education. Since this research was done in Turkey, the disparity in Turkey's treatment policies and those in the United States will be a weakness. The findings, however, are also widely applicable to TB treatment. ${ }^{16}$

Overall, these results illustrate shortcomings in clinical services that result in TB treatment of those populations most vulnerable to the disease being of below standard quality. Improving the standard of care requires not only trained, accessible and motivated personnel but also linking the community pharmacists and clinical pharmacists into the framework of health services. Indian community pharmacists are particularly involved in dispensing of anti-TB drugs in the field of treatment, through their thorough training and understanding of drugs in terms of clinical pharmacy services. This pharmaceutical operation has brought in patientcentered clinical activities, a core aspect of which are clinical interventions in the community pharmacies sector.

The Community pharmacist carried out a prescription drug study with the possibility of reviewing the medical histories of patients with TB along with the clinical response and medical background of patients where these details and analyzes were required. If this detail is not contained in the medical report, the community pharmacist has demanded such details from the clinical pharmacist.

Multidrug-resistant TB and extensively drug-resistant TB have been described as major threats to public safety that call for improved efforts to control TB. ${ }^{17}$ Pharmacists have been recommended to play a larger role in TB treatment by promoting commitment to drugs; evaluating patients for risk factors for resistant diseases; presenting knowledge on disease management and prevention; and surveillance for effectiveness, adverse effects and DDIs. ${ }^{18}$

In our study, the participation of community pharmacists and clinical pharmacists of TB Patient monitoring provided for identification of the medication adherence concerning quality of life, the main is patient satisfaction of collaborative intervention of community and clinical pharmacist. There is increased compliance of clinical services with expertise in the management in TB management usage of the MMAS-8 Scale for Morisky Drug Adherence, FACIT- Satisfaction with Pharmacist scale, Health-related QoL (SF-12) Scale. 
For future study, we recommend clinical pharmacist attitudes towards cooperation with community pharmacists to strengthen the treatment of patients for future research. We are also proposing to identify obstacles to collaboration. This continued emphasis on cooperation will allow TB management's clinical delivery services to be optimized.

\section{CONCLUSION}

We noticed that the community pharmacists who took part in our research demonstrated a clear tendency to cooperate with clinical pharmacist, but that disposition has not yet been reciprocal. Community pharmacists must also become acquainted with professional interactions in the health system of TB during their educational classes, during their continuing education in pharmacy and after graduation and try to eliminate the existing imperfections. Furthermore, the curriculum at pharmacy schools could be improved by training community pharmacists to better collaborate with clinical pharmacist.

\section{ACKNOWLEDGEMENT}

The authors are thankful to the Vice-Chancellor, KLE Academy of Higher Education and Research, Belagavi. The present study is a Ph.D. thesis in the field of Community pharmacist education.

\section{CONFLICT OF INTEREST}

All authors approved the manuscript and this submission. The author reported no conflict of interest and no funding was received for this work.

\section{ABBREVIATIONS}

MMAS-8: Morisky Medication Adherence Scale; FACIT - SWIP: Functional Assessment of Chronic Illness Therapy - Satisfaction with Pharmacist Scale; SF-12: Short Form Survey; TB: Tuberculosis; QoL: Quality of life; KAP: Knowledge, Attitude and Practice; WHO: World health organization; PPM: Public-Private Mix.

\section{REFERENCES}

1. Saavedra-Mitjans M, Ferrand É, Garin N, Bussières JF. Role and impact of pharmacists in Spain: A scoping review. International Journal of Clinical Pharmacy. 2018;40(6):1430-42.

2. Basak SC, Mil JWV, Sathyanarayana D. The changing roles of pharmacists in community pharmacies: Perception of reality in India. Pharmacy World and Science. 2009;31(6):612-8.

3. Fang $\mathrm{Y}$, Yang S, Zhou S, Jiang M, Liu J. Community pharmacy practice in China: Past, present and future. International Journal of Clinical Pharmacy. 2013;35(4):520-8.

4. Moussavi K, Nikitenko V. Pharmacist impact on time to antibiotic administration in patients with sepsis in an ED. American Journal of Emergency Medicine. 2016;34(11):2117-21.

5. Pawluk S, Jaam M, Hazi F, AlHail MS, ElKassem W, et al. A description of medication errors reported by pharmacists in a neonatal intensive care unit. International Journal of Clinical Pharmacy. 2016;39(1):88-94.

6. Marra, C, Johnston K, Santschi V, Tsuyuki RT. Cost-effectiveness of pharmacist care for managing hypertension in Canada. Canadian Pharmacists Journal. 2017;150(3):184-97.

7. Schimmelfing JT, Brookhart AL, Fountain KM, Goode JK. Pharmacist intervention in patient selection of nonprescription and self-care products. Journal of the American Pharmacists Association. 2017;57(1):86-9.

8. Krass I, Armour CL, Mitchell B, Brillant M, Dienaar R. The Pharmacy Diabetes Care Program: Assessment of a community pharmacy diabetes service model in Australia. Diabetic Medicine. 2007;24(6):677-83.

9. Brink AJ, Messina AP, Feldman C, Richards GA, Becker PJ. Antimicrobial stewardship across 47 South African hospitals: An implementation study. The Lancet Infectious Diseases. 2016;16 (9):1017-25

10. Sokol MC, McGuigan KA, Verbrugge RR, Epstein RS. Impact of medication adherence on hospitalization risk and healthcare cost. Medical Care. 2005;43(6):521-30.

11. WHO. Engaging all health care providers in TB control. Guidance on implementing public-private mix approaches. Geneva: World Health Organization. 2006.

12. Morisky DE, Ang A, Krousel-Wood M, Ward HJ. Predictive validity of a medication adherence measure in an outpatient setting. Journal of Clinical Hypertension. 2008;10(5):348-54.

13. Hernández L, Chang $\mathrm{CH}$, Cella D, Corona M, Shiomoto G, McGuire DB Development and Validation of the Satisfaction with Pharmacist Scale. Pharmacotherapy. 2000;20(7):837-43.

14. Ware JE, Kosinski M, Keller SD. How to Score the SF-12 Physical and Mental Health Summary Scales, $2^{\text {nd }}$ end. Boston: Health Institute, New England Medical Center. 1995.

15. Hess K, Goad J, Wu J, Johnson K. Isoniazid Completion Rates for Latent Tuberculosis Infection among College Students Managed by a Community Pharmacist. Journal of American College Health. 2009;57(5):553-5.

16. Clark PM, Karagoz T, Apikoglu-Rabus S, Izzettin FV. Effect of pharmacist-led patient education on adherence to tuberculosis treatment. American Journal of Health-System Pharmacy. 2007;64(5):497-505.

17. Gandhi NR, Nunn P, Dheda K, Schaaf HS, Zignol M. Multidrug-resistant and extensively drug-resistant tuberculosis: A threat to global control of tuberculosis. Lancet. 2010;375(9728):1830-43.

18. Mkele G. The role of the pharmacist in TB management. South African Pharmaceutical Journal. 2010;77(2):18-21. 


\section{PICTORIAL ABSTRACT}

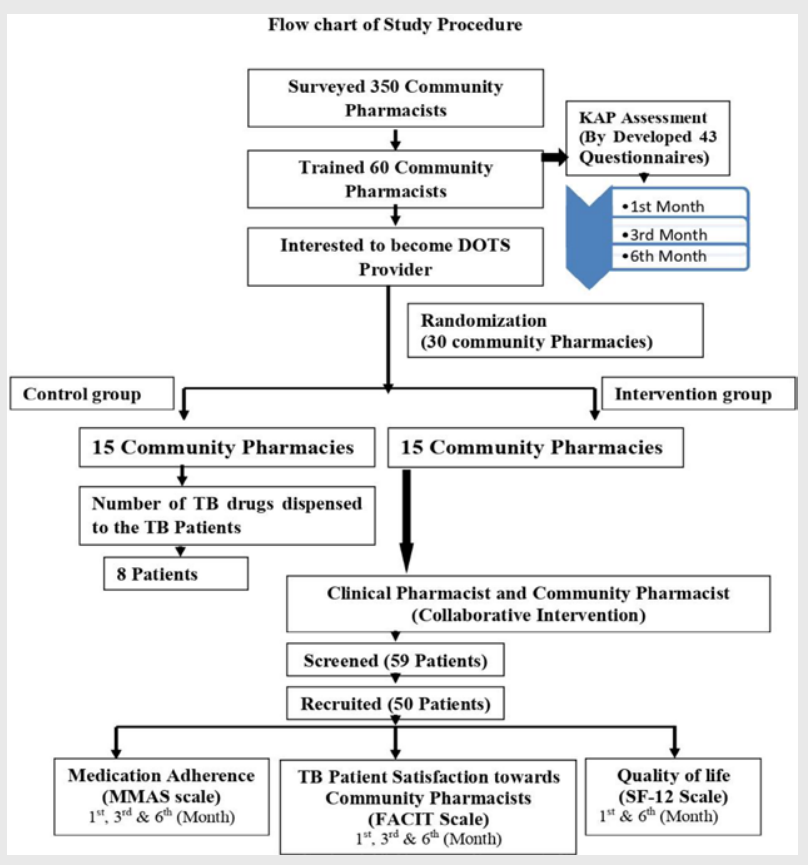

\section{SUMMARY}

- The overall increase in Knowledge, Attitude and Practice of Community Pharmacists in Treating Tuberculosis patients.

- Periodically training or courses are required to update the knowledge and skills of community pharmacists.

- Collaborating community pharmacist and clinical pharmacist in treating tuberculosis patients shows the best outcome in terms of Quality of life and Medication adherence are shows better outcome.

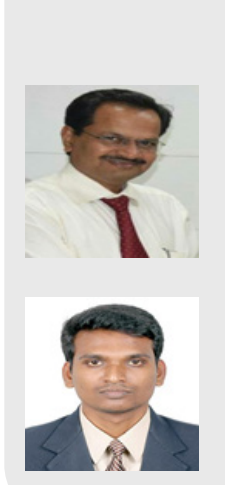

\section{About Authors}

Dr. M S Ganachari, Professor and Head, Department of Pharmacy Practice, KLE College of Pharmacy, Belagavi. He is currently holding key positions of Dean, Faculty of Pharmacy, Deputy Registrar, KLE Academy of Higher Education and Research, Belagavi, INDIA. He is having 29 years of teaching experience.

Dr. Uday Kumar R, He is a Doctoral student from the Department of Pharmacy Practice, KLE College of Pharmacy, KLE Academy of Higher Education and Research, Belagavi, INDIA. He has Completed Pharm.D from Rajiv Gandhi University of Health Sciences, Bangalore, INDIA. His area of interest is Tuberculosis research.

Cite this article: Rangaswamy UK, Ganachari MS. Community Pharmacist and Clinical Pharmacist Interventions using MMAS-8, FACIT, SF-12 among Pulmonary TB Patients Receiving Anti-TB Drugs from Urban Community Pharmacies, South India. Indian J of Pharmaceutical Education and Research. 2020;54(4):1184-92. 